\title{
A unique pulmonary venous abnormality: with associated pulmonary arterial anomaly and arteriovenous malformation
}

\author{
M I CHA EL HONEY, M I CHA L C. PEARSON, \\ and J.N.PAT TINSON \\ Departments of Cardiology and Radiology, Brompton Hospital, London SW3, \\ and London Chest Hospital, London E2
}

\begin{abstract}
Honey, M., Pearson, M. C., and Pattinson, J. N. (1976). Thorax, 31, 190-196. A unique pulmonary venous abnormality: with associated pulmonary arterial anomaly and arteriovenous malformation. A man aged 29 was first seen at the age of 11 , when he was found to have a congenital anomaly of the pulmonary veins which follow an abnormal course to the hilum. On the left side, two large veins descend peripherally before turning medially towards the left atrium; on the right, several smaller veins follow a similar circuitous route from the periphery, before uniting into two main veins which enter the left atrium. The proximal pulmonary arteries are normal in their pattern of branching and distribution but are dilated and tortuous and taper abruptly: the left lower lobe artery is abnormally large almost down to the diaphragm. There is also a systemic arterio/pulmonary venous fistula. There is no haemodynamic disturbance, but gas transfer is slightly impaired, and there is slight arterial desaturation.

This congenital anomaly is unique. Reported cases described as having pulmonary venous varices are a heterogeneous group, but one patient described as such shows resemblances to our case.
\end{abstract}

The patient reported here has a hitherto undescribed pulmonary venous abnormality, in which all the major pulmonary veins follow a very abnormal intrapulmonary course but drain normally into the left atrium. This was associated with abnormal pulmonary arteries and a systemic arterio/pulmonary venous malformation in the right lung, arising from the descending aorta.

\section{CASE REPORT}

The patient, now 29 years old, was first seen as a boy of 11 in 1956 after a pulmonary vascular abnormality had been recognized at the local chest clinic following mass radiography at school. He was symptomless. A continuous murmur was heard below the right clavicle, but there were no other abnormal physical signs. After investigation he remained under observation as an outpatient for six years. He was re-examined at the age of 25, when no change was found. In 1972 he was refused life assurance and was then re-admitted for further investigation. He still has no symptoms of cardiovascular or respiratory disease but has recently developed migraine associated with transient visual field defect, aphasia, and 0 hemianaesthesia.

On examination in 1973 there was no cyanosis $\frac{\dot{\sigma}}{3}$ nor clubbing. The arterial pulse was normal and $\stackrel{3}{\text {. }}$ regular, and the blood pressure $150 / 90 \mathrm{mmHg}$. The venous pressure and pulse were normal. There $₹$ was still a quiet continuous murmur heard in the second right intercostal space and below the right $\supset$ clavicle. The heart was not enlarged; the heart sounds were normal, and there were no other o murmurs. The lungs were clinically normal.

The electrocardiogram showed borderline vol- $\tilde{N}$ tage changes of left ventricular hypertrophy but $\mathbb{\omega}_{\mathrm{N}}$ was otherwise normal. The chest radiograph is described below and illustrated (Fig. 1).

Cardiac catheterization (Table I) showed normal $\stackrel{\overbrace{}}{\mathbb{D}}$ intracardiac pressures. There was no detectable $\stackrel{\oplus}{+}$ left-to-right shunt, but arterial blood gas analysis showed a slightly reduced oxygen tension. The $\stackrel{\vec{D}}{\mathbb{D}}$ pulmonary arteriogram and aortogram are described below. Respiratory function tests (Table II) $\mathbb{Q}$ showed no significant ventilatory abnormality, but gas transfer was slightly reduced. 


\section{RADIOLOGICAL OBSERVATIONS}

The 1956 chest radiograph shows a normal heart size and cardiac contour. The right hilar vessels are prominent, but peripherally in the right lung the vessels are normal in size. On the left side the upper lobe vessels appear enlarged, and a large artery is visible behind the heart. Two abnormal vessels, presumably venous, pass vertically downwards before making an abrupt turn medially towards the heart. A previous film in 1947 had shown slight cardiac enlargement, and the abnormal vascular pattern could be recognized in retrospect. Serial chest radiographs between 1956 and

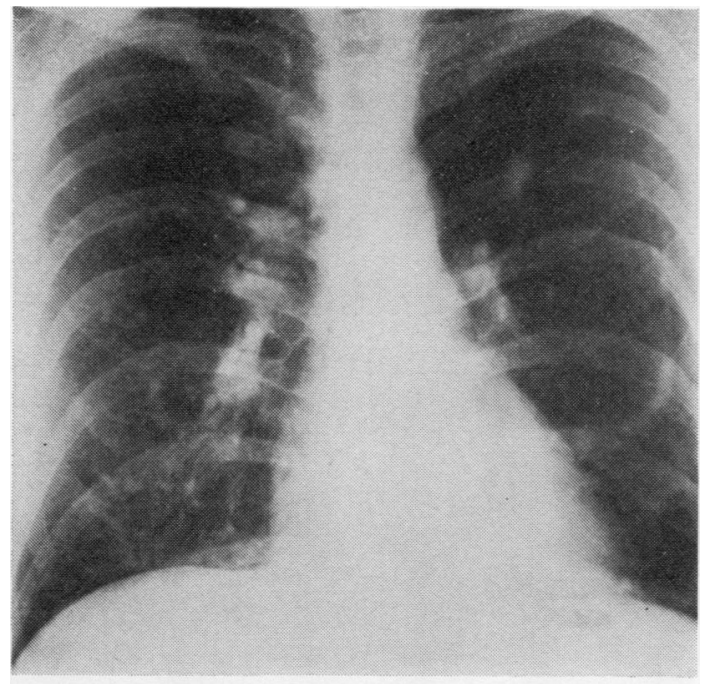

(a)

FIG. 1. (a) Chest radiograph in 1973;

1973 show no significant change though the abnormal vessels are more clearly seen (Fig. 1).

Pulmonary angiograms were obtained in 1956 by peripheral venous injection, and in 1973 by selective injection into the main pulmonary trunk. These show the proximal pulmonary arteries to be tortuous and enlarged but normal in anatomical distribution. With the exception of the left lower lobe artery, the arterial calibre decreases suddenly at the subsegmental level; the left lower lobe artery remains large until just above the diaphragm where it divides into several small branches (Fig. 2).

The pulmonary veins are grossly abnormal (Fig. 3). On the left side, middle and lower veins course vertically downwards peripherally before turning sharply inwards towards the heart; an

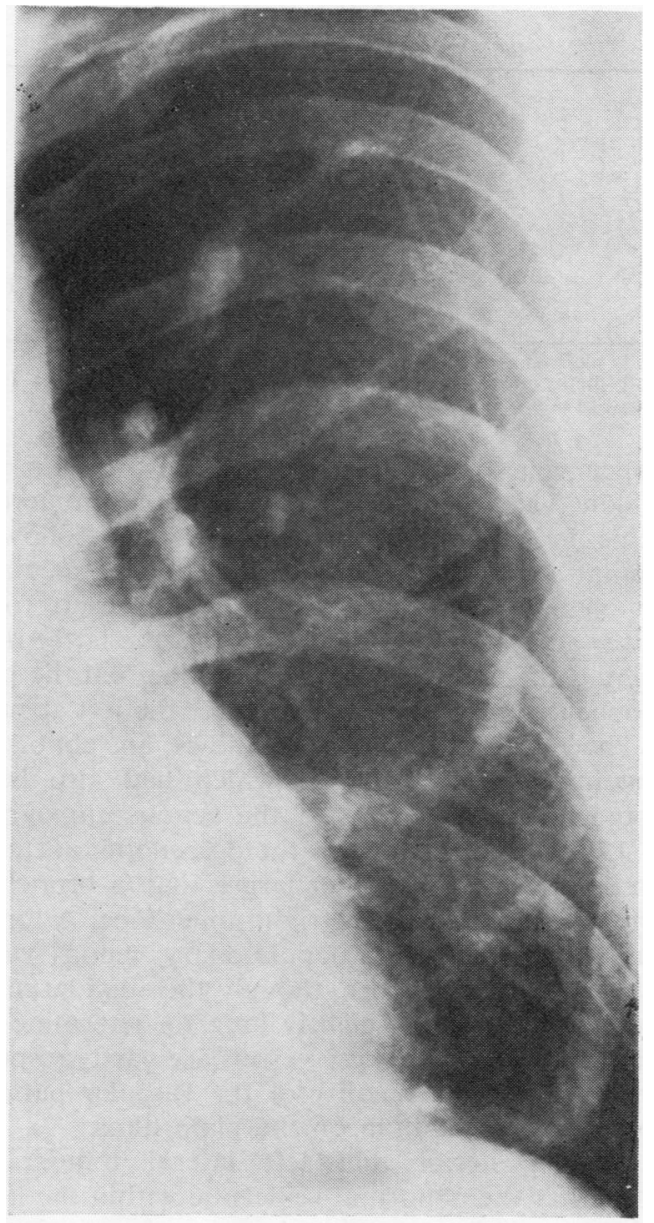

(b)

(b) magnified view of left hemithorax.

T A B L E I

CARDIAC CATHETERIZATION DATA

\begin{tabular}{|c|c|c|}
\hline Site & Pressure $(\mathrm{mmHg})^{1}$ & $\begin{array}{l}\text { Oxygen } \\
\text { Saturation } \\
\text { per cent }\end{array}$ \\
\hline $\begin{array}{l}\text { SVC } \\
\text { IVC } \\
\text { RA } \\
\text { RV } \\
\text { PA } \\
\text { PA wedge } \\
\text { LV } \\
\text { Aorta }\end{array}$ & $\begin{array}{l}\text { a } 9, \text { x } 2, \text { v } 7, \text { y } 5 \text {, mean } 6 \\
27 / 4-9 \\
26 / 13 \text {, mean } 19 \\
\text { a } 14, \times 10, \text { v } 14, \text { y } 10, \text { mean } 12 \\
160 / 7-16^{2} \\
160 / 100^{2}\end{array}$ & $\begin{array}{l}66 \\
69,74 \\
70 \\
73 \\
73 \\
96\end{array}$ \\
\hline
\end{tabular}

Oxygen consumption $129 \mathrm{ml} / \mathrm{min}$ per $\mathrm{m}^{2}$ BSA

Cardiac index $2.81 / \mathrm{min}$ per $\mathrm{m}^{2}$ BSA

Pulmonary arteriolar resistance 2.5 units per $\mathrm{m}^{2}$ BSA

${ }^{1}$ Reference zero: mid-thorax.

Conversion to Pascal units: $1 \mathrm{mmHg} \approx 0.133 \mathrm{kPa}$

2 After angiography. 
T A B L E I I

RESPIRATORY FUNCTION TESTS

\begin{tabular}{|c|c|}
\hline $\begin{array}{l}\text { FEV } \\
\text { FVC } \\
\text { FEV } 1 \text { FVC } \\
\text { VC1 } \\
\text { FRC' } \\
\text { TLC1 } \\
\text { RV/TLC } \\
\text { Airways resistance } \\
\text { SGaw } \\
\text { TFi } \\
\text { PaO, }^{3}\end{array}$ & $\begin{array}{l}3410 \mathrm{ml} \\
3740 \mathrm{ml} \\
91 \% \\
3800 \mathrm{ml} \\
3760 \mathrm{ml} \\
6340 \mathrm{ml} \\
40 \% \\
2 \cdot 59 \mathrm{cmH}_{2} \mathrm{O}^{-1} \mathrm{~s}\left(0 \cdot 259 \mathrm{kPa}^{-1} \mathrm{~s}\right) \\
0.103 \mathrm{~s}^{-1} \mathrm{cmH}_{2} \mathrm{O}^{-1}\left(1.03 \mathrm{~s}^{-1} \mathrm{kPa}^{-1}\right) \\
24 \cdot 2 \mathrm{ml} \mathrm{min}^{-1} \mathrm{mmHg}^{-1}\left(8 \cdot 0 \mathrm{mmol}^{-1} \mathrm{~min}^{-1} \mathrm{kPa}^{-1}\right) \\
\left.70 \mathrm{mmHg}^{\circ} \cdot 3 \mathrm{kPa}\right)\end{array}$ \\
\hline
\end{tabular}

${ }^{1}$ Body plethysmograph (DuBois et al., 1956).

'Body plethysmograph (DuBois et al., 1956; Briscoe and DuBois, 1958). ${ }^{\text {a }}$ Single breath method of Ogilvie et al. (1957).

upper vein descends more medially to join the middle vein. On the right side, more numerous veins in the middle and lower zones follow a similar course, descending before turning medially or medially and upwards; these unite to form lower and middle pulmonary veins, the latter then joining the vein from the upper lobe. All the pulmonary veins can be seen to enter the left atrium.

The aortogram in 1973 shows an abnormal systemic artery (Fig. 4a) which had also been noted on the late films of the venous angiogram in 1956. This arises from the descending aorta, is similar in position to but larger than a bronchial artery, and passes to the right upper lobe. A tortuous vessel resembling a pulmonary venous varix fills from it (Fig. 4b), though the angiographic sequence is not sufficiently long to determine its final drainage site. These vessels are partly responsible for the abnormality of the vascular pattern above the right hilum on the plain films.

Anteroposterior and left lateral tomograms show that the abnormal vessels lie within the lung substance and not on the pleural surface or in the fissures. They also show calcification in the wall of the draining vein of the systemic arterio/ pulmonary venous malformation (Fig. 5).

\section{DISCUSSION}

This patient has an abnormality of the pulmonary veins unlike any other we have found in the literature. Normal pulmonary veins take a direct course from the periphery to the hilum of the lung. In our case, abnormal pulmonary veins descend towards the bases before turning medially or medially and upwards: on the left side, there are three major vessels, the upper and middle of which unite before entering the left atrium; on the right side, there are multiple abnormal veins, dilated, elongated, and sinuous, but generally not tortuous, which join to constitute middle and lower veins, the former then joining a relatively normal upper

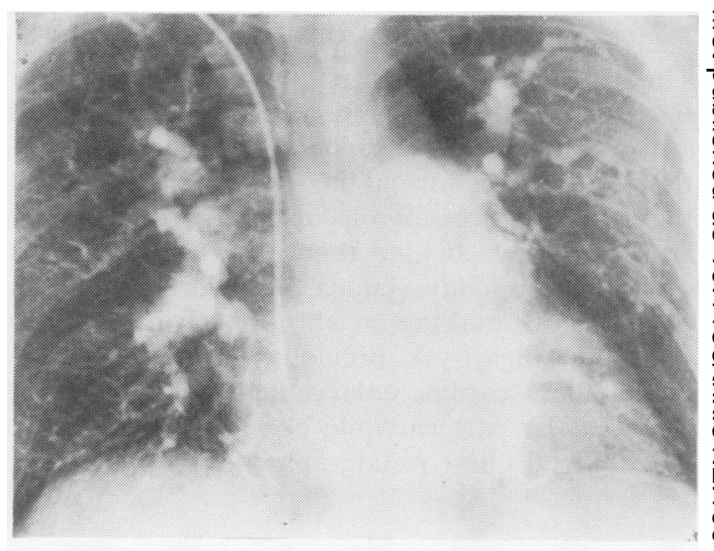

(a)

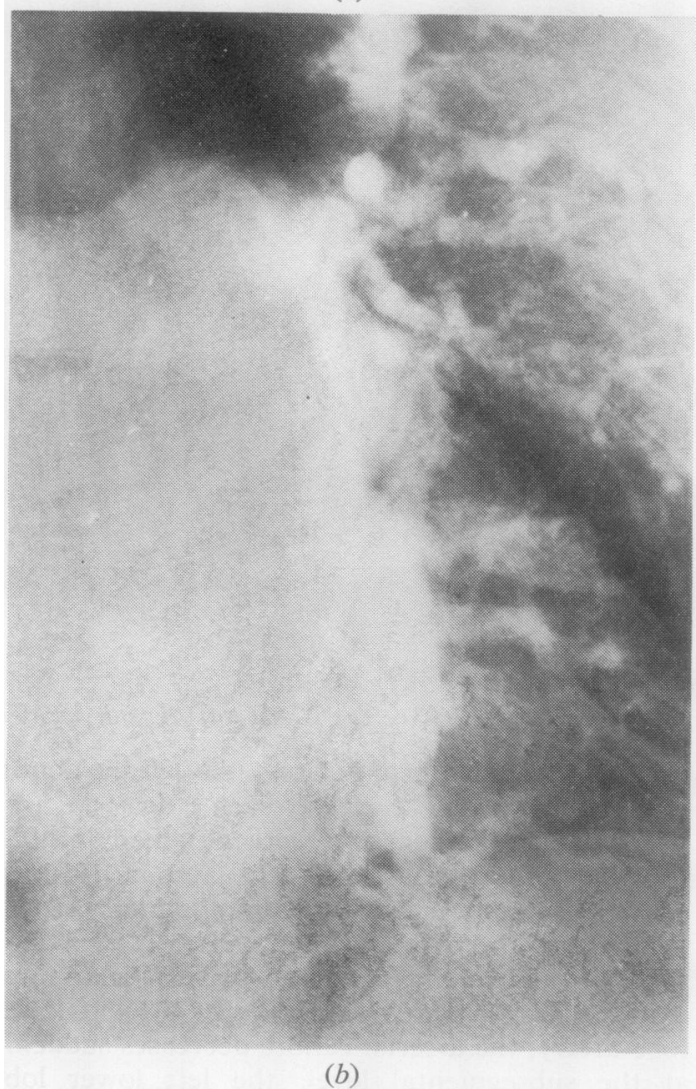

FIG. 2. (a) Pulmonary arteriogram: arterial phase; (b) magnified view of left lower and middle zones.

pulmonary vein. In addition, the proximal pulmonary arteries are abnormal in appearance, being dilated and tortuous, and tapering abruptly, and the left lower lobe artery is very large, though the 


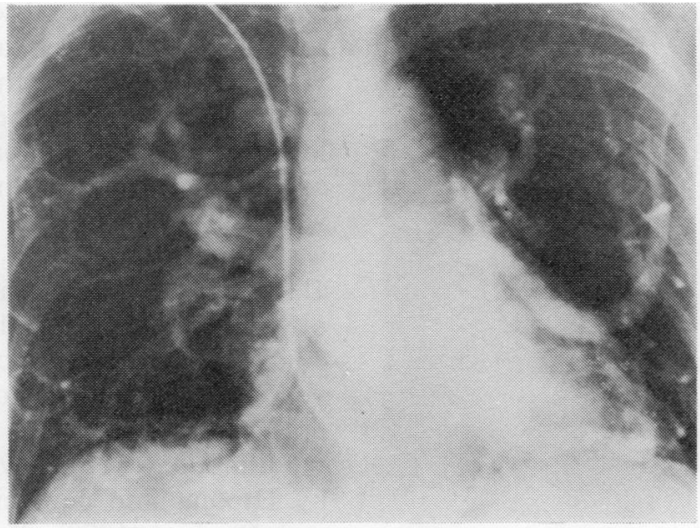

(a)

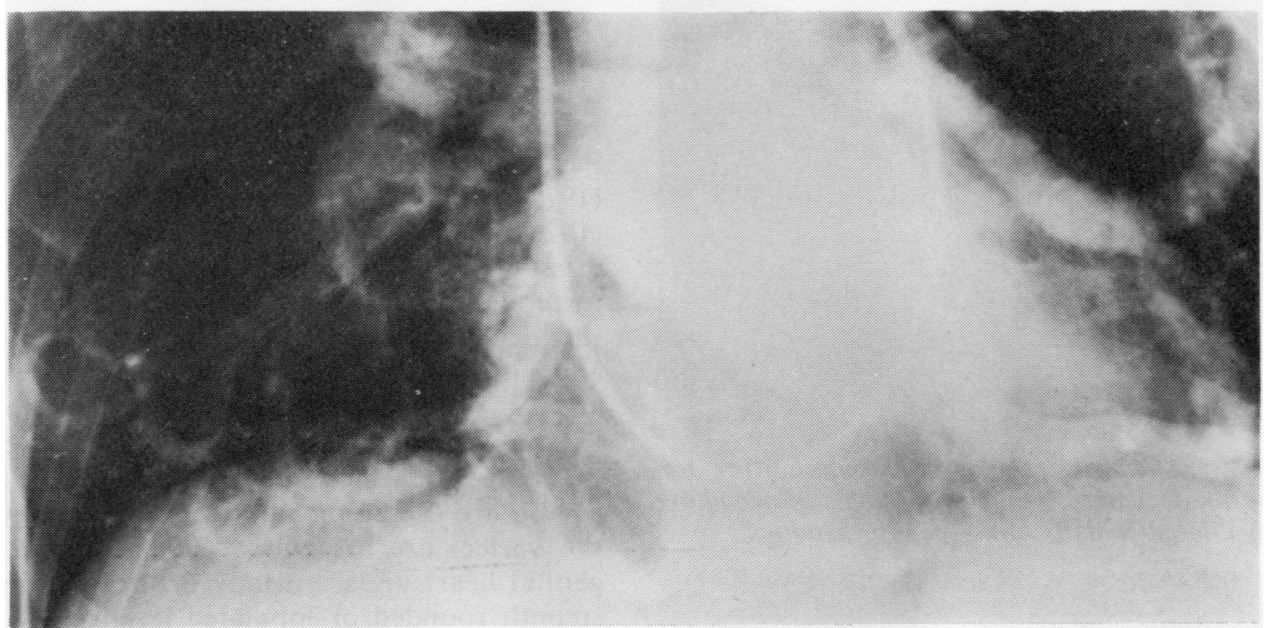

(b)

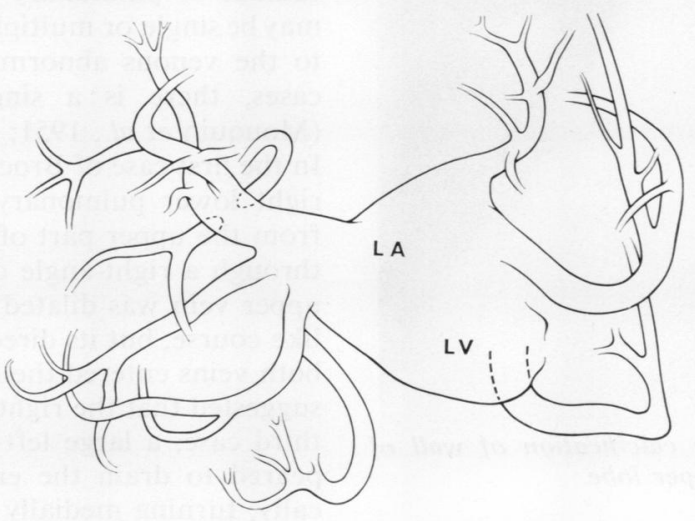

(c)

FIG. 3. (a) Pulmonary arteriogram: venous phase; (b) magnified view of lower half of both lungs; (c) line drawing of pulmonary veins. 


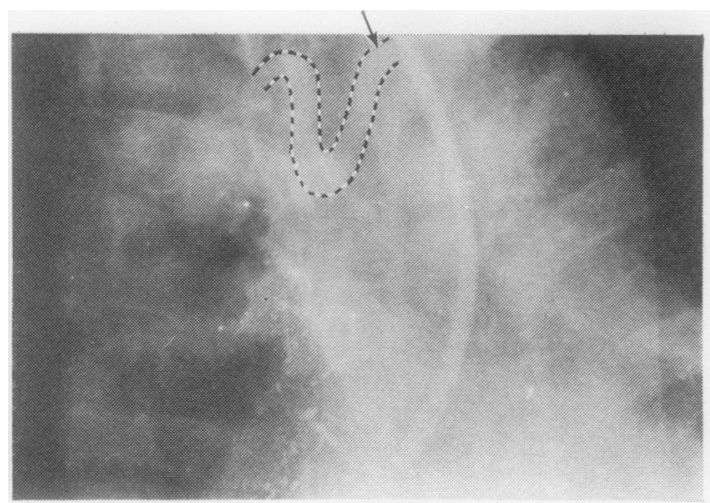

(a)

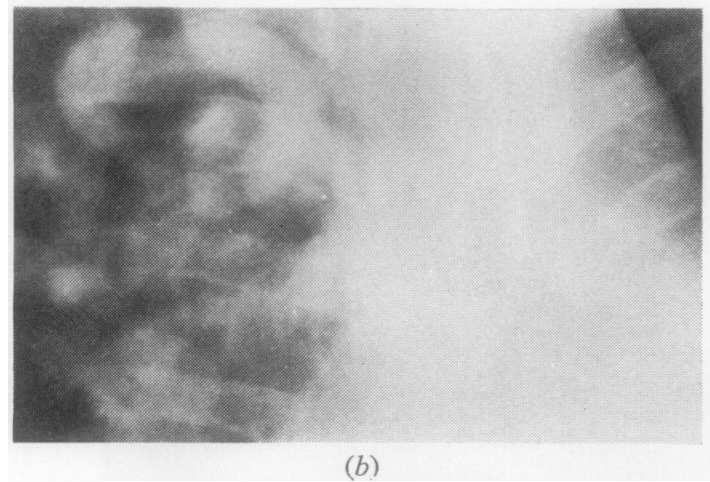

FIG. 4. (a) Aortogram: arterial phase, showing tortuous systemic artery; (b) aortogram: venous phase, showing dilated and tortuous venous channel.

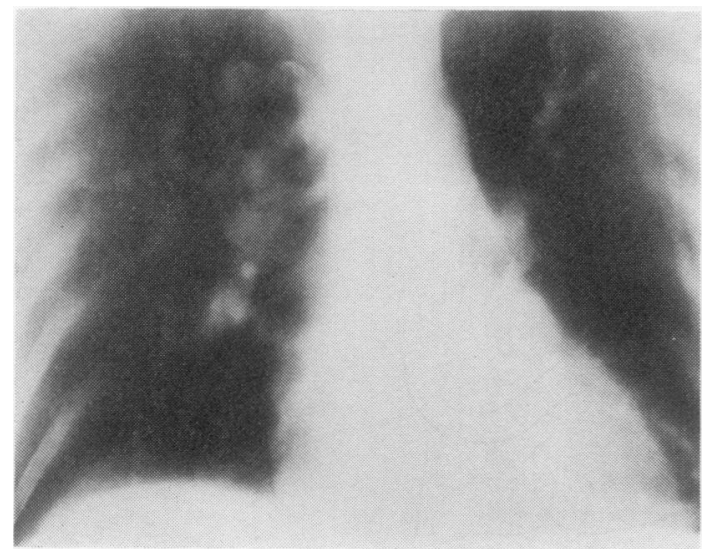

FIG. 5. Tomogram showing calcification of wall of venous varicosity in right upper lobe.

course and distribution of the vessels is normal. These changes resemble those seen in pulmonary arterial hypertension which has been shown not to be present. In the absence of pulmonary hypertension they suggest a structural defect of the vessel wall. Finally, there is a systemic arterio/흘 pulmonary venous anomaly in the right upper, lobe. Abnormal pulmonary veins on the left side $\stackrel{\mathbb{Q}}{\Omega}$ and the vascular anomaly above the right hilumg were apparent on the earliest radiograph taken $\rightarrow$ when the patient was only 3 years old. Though? all the radiological changes have become more $\vec{\omega}$ obvious as the patient has grown, there can be noo doubt that the pulmonary arterial, pulmonary $\vec{x}$ venous, and arteriovenous anomalies have all beenc present from birth.

Pulmonary venous varices have been reported by Hipona and Jamshidi (1967), Rizk, Melhem, $\stackrel{\bullet}{\circ}$ and Dagher (1970), Brocard, Vannier, and Gal-o louedec (1970), and Bartram and Strickland(1971), and these authors have reviewed a number $>$ of similar malformations recorded in the literature. Further cases have been reported more $\overrightarrow{0}$ recently by Papamichael et al. (1972), Castelló Pérez Gómez, and Marazuela (1972), Beamish (1972), Perrott and Shin (1974), and Davia et al.O (1974) These varices vary greatly: they ares usually dilated, elongated, and more or lesso tortuous proximal pulmonary veins, draining a요 single lobe or segment but following an essentially normal course; the peripheral ramifications $\overrightarrow{\vec{O}}$ are normal. The dilatation may be localized, 3 forming a sac, or may extend along the length of the vein. The other pulmonary veins are normal, as also are the pulmonary arteries. In a few cases, the varices are associated with acquired or con-을 genital heart disease. Many of these present withx smooth rounded or lobulated lesions seen on the plain chest radiograph which may resemble. tumour or pulmonary arteriovenous fistula; these may be single or multiple but show no resemblance to the venous abnormality in this case. In othero cases, there is a single dilated, tortuous vein (Mouquin et al., 1951; Kozuka and Nosaki, 1968). In the first case of Brocard et al. (1970), the dilated right lower pulmonary vein descended vertically from the upper part of the lung, turning medially through a right-angle close to the diaphragm; thew upper vein was dilated and followed a corkscrew like course, but its direction was generally normal, both veins entered the left atrium. Bronchography suggested that the right lung was unilobar. In their ${ }^{+}$ third case, a large left pulmonary vein which appeared to drain the entire lung descended verti- $\frac{\text { o }}{D}$ cally, turning medially and then upwards to enter? the left atrium. In their second case, also with å hypoplastic right lung, an anomalous right pul-0 monary vein entered the inferior vena cava, ando 
a second vein draining the right lung was said to follow an abnormal course to the left atrium but is not clearly shown in their illustration. On the basis of their experience, Brocard et al. (1970) suggest that pulmonary varices of the type they have encountered are usually part of a complex malformation, involving also pulmonary arteries and bronchi, and as such are related to the scimitar syndrome. Though there are points of similarity, none of these cases closely resembles the one we have described.

On the other hand, Kaindl, Kotscher, and Lobenwein (1971) have described a patient in whom the pulmonary venous abnormality is more like that seen in our patient. In their case 4 , the right lung veins were dilated and unusually long, and followed a sinuous course from periphery to hilum with siphon-like loops turning back on themselves and few branches. The central pulmonary veins were normal and entered the left atrium. The pulmonary venous anatomy on the left side is not well shown on their illustrations. As in our case, the proximal pulmonary arteries on both sides were dilated and tortuous.

Our view is that the pulmonary venous abnormality in our case represents a congenital anomaly of the course and distribution of the pulmonary veins. The pulmonary venous system evolves from a primitive plexus on the ventral aspect of the lung bud of the embryo. We can offer no explanation of the factors determining the pattern and course of the lobar and segmental veins either in the normal lung or in our case. At an early stage in development there are anastomoses between the pulmonary plexus and the posterior and common cardinal veins, which may persist and lead to partial anomalous pulmonary venous drainage to systemic veins on either side. In our case, though the development of the normal direct pathway to the hilum of the lung has been inhibited by some unknown mechanism, the alternative and circuitous route reaches a normal destination.

This curious pulmonary venous anomaly has not resulted in any haemodynamic disturbance and indeed none would be expected. It seems likely that the slightly reduced arterial oxygen tension and saturation results from a ventilation/perfusion imbalance. Though distribution of ventilation has not been measured, there is no significant disturbance of overall pulmonary ventilation, and it is probable that the distortion of the orderly anatomical pattern of pulmonary venous drainage has resulted in an abnormal distribution of pulmonary perfusion. The resulting impairment of gas exchange is, however, slight, unaccompanied by any subjective disability and unlikely to affect prognosis adversely. Though haemorrhage from pulmonary varices is reported, this has occurred in those patients in whom the varix is localized and sac-like, and there seems to be no reason to anticipate this complication in our case. Possibly, however, reduced velocity of blood flow and the late development of degenerative changes in the vein wall might predispose to pulmonary venous thrombosis. It is unlikely that the development of migraine albeit with severe prodromal symptoms is related in any way to the pulmonary venous anomaly, though a congenital cerebral vascular lesion has not been excluded.

\section{REFERENCES}

Bartram, C. and Strickland, B. (1971). Pulmonary varices. British Journal of Radiology, 44, 927.

Beamish, W. E. (1972). Pulmonary venous varicosity. Journal of the Canadian Association of Radiologists, 23, 136.

Briscoe, W. A. and DuBois, A. B. (1958). The relationship between airway resistance, airway conductance, and lung volume in subjects of different age and body size. Journal of Clinical Investigation, 37, 1279.

Brocard, H., Vannier, R., and Gallouedec, Ch. (1970). Les varices pulmonaires, éléments possibles d'anomalies pulmonaires congénitales complexes. Annales de Médecine Interne, 121, 217.

Castelló, J., Pérez Gómez, F., and Marazuela, A. (1972). Varicosided pulmonar. Revista Espanola de Cardiologia, 25, 175.

Davia, J. E., Golden, M. S., Price, H. L., Hastings, J. E., and Cheitlin, M. D. (1974). Pulmonary varix: a diagnostic pitfall. Circulation, 49, 1011.

DuBois, A. B., Botelho, S. Y., Bedell, G. N., Marshall, R., and Comroe, J. H. Jr. (1956). A rapid plethysmographic method for measuring thoracic gas volume: a comparison with a nitrogen washout method for measuring functional residual capacity in normal subjects. Journal of Clinical Investigation, 35, 322 .

- - $\longrightarrow$, and Comroe, J. H. Jr. (1956). A new method for measuring airway resistance in man using a body plethysmograph: values in normal subjects and in patients with respiratory disease. Journal of Clinical Investigation, 35, 327.

Hipona, F. A. and Jamshidi, A. (1967). Observations on the natural history of varicosity of pulmonary veins. Circulation, 35, 471.

Kaindl, F., Kotscher, E., and Lobenwein, E. (1971). Zur Radiologie pulmonaler Gefässfehlbildungen. Radiologe, 11, 189.

Kozuka, T. and Nosaki, T. (1968). A pulmonary vein anomaly: unusual connection and tortuosity of the right lower lobe vein. British Journal of Radiology, 41, 232. 
Mouquin, M., Hébrard, H., Damasio, R., Jouvet, P., Durand, M., and Piéquet, J. (1951). Varice du poumon diagnostiquée par l'angiocardiographie. Bulletins et Mémoires de la Société Médicale des Hôpitaux de Paris, 67, 1091.

Ogilvie, C. M., Forster, R. E., Blakemore, W. S., and Morton, J. W. (1957). A standardized breath holding technique for the clinical measurement of the diffusing capacity of the lung for carbon monoxide. Journal of Clinical Investigation, 36, 1.

Papamichael, E., Ikkos, D., Alkalais, K., and Yannacopoulos, J. (1972). Pulmonary varicosity associ- ated with other congenital abnormalities. Chest, $\overrightarrow{\overrightarrow{\vec{\omega}}}$ 62, 107.

Perrott, W. W., and Shin, M. S. (1974). Pulmonary varix. Journal of Thoracic and Cardiovascular Surgery, 68, 318.

Rizk, G., Melhem, R., and Dagher, I. (1970). Bilateral@ pulmonary varicosities associated with coarctation of the aorta. Thorax, 25, 97.

Requests for reprints to: Dr. Michael Honey, Bromp-ç ton Hospital, Fulham Road, London SW3. 